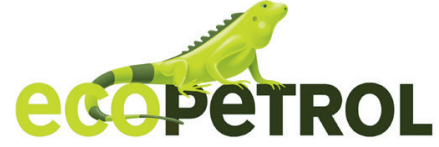

ctyf@ecopetrol.com.co

\title{
ASSESSMENT OF CAUSES OF OVERPRESSURE DIFFERENT FROM SUB-COMPACTION: APPLICATION IN UNCONVENTIONAL RESERVOIRS
}

Vargas-Silva, Diego,Armando ${ }^{a *}$; Gambús-Ordaz, Maika ; Calderón-Carrillo, Zuly ${ }^{a}$

\begin{abstract}
The need of hydrocarbon producing countries to increase reserves has led energy companies to explore the deposits available in source rocks that might be over-pressured and thus, strict rules are required for their development. Overpressure, which may result in wellbore stability problems, could result from several causes such as mechanical effects, dynamic transfer, chemical stress, thermal stress, among others, in which undercompaction is frequently the main cause, generated when the sediment deposition velocity exceeds the fluid ejection rate. The expansion of fluids generated by thermal stresses and the reduction of porosity caused by chemical stresses may be among the other causes of overpressure in shales.
\end{abstract}

The new methodology presented in this paper makes it possible to determine the pressure due to thermal stresses caused by the cracking of kerogen and oil in shales. In addition, petrophysical and geochemical models are considered in order to precisely ascertain the increase in pore pressure due to temperature and fluid expansion. An increase of $20 \%$ in pressure is seen when compared with undercompaction. As a result of this methodology, the mud window was optimized and the hydrocarbons, generated under subsurface the conditions (pressure, temperature) analysed, were quantified.

\section{RESUMEN}

La necesidad de los países productores de hidrocarburos por incrementar sus reservas, ha conducido a las empresas del sector energético a explorar los yacimientos de roca generadora, los cuales, pueden estar sobrepresionados, obligando a establecer reglas estrictas para su desarrollo. Problemas de estabilidad de pozos pueden ser generados por esta sobrepresión, que es causada por esfuerzos mecánicos, la transferencia dinámica, esfuerzos químicos, termales, entre otros; siendo la sub-compactación la causa principal, generada cuando la velocidad de deposición del sedimento excede la velocidad de expulsión del fluido. Específicamente, al estudiar los Shales se deben incluir causas adicionales que propician tal sobrepresión, entre estas causas se puede citar, la expansión de fluidos generada por los esfuerzos térmicos y la reducción de la porosidad causada por esfuerzos químicos.

Este trabajo presenta una metodología novedosa, que permite determinar la presión de poro incluyendo los esfuerzos térmicos originados por el craqueo del kerógeno y el aceite en el shale. Además, considera el acople de los modelos petrofísico y geoquímico, con la finalidad de conocer en profundidad el incremento de la presión de poro, debido a la temperatura y la expansión de fluidos. Como resultado, se evidencia un aumento de la presión de poro del 20\%, en comparación a sólo considerarse la sub-compactación como variable de influencia. Con esta metodología se optimizan las ventanas de estabilidad y se cuantifican los hidrocarburos que pudieron generarse bajo las condiciones de presión y temperatura analizadas. 


\section{INTRODUCTION}

In recent decades, estimating pore pressures in sedimentary basins has become one of the most critical and important variables in the planning of drilling projects within the oil industry. This is particularly important when it comes to difficult areas of study, such as unconventional deposits; especially shales. Drilling success depends on the stability window, which requires precise knowledge of the expected pore pressure. This allows to determine a safe range of mud densities, with a view to avoiding problems during drilling.

Since the 50s, analytical models have been available for estimating pore pressure. Their use is limited by consideration of subcompaction as the main mechanism of overpressure generation. Some examples of these models, which estimate overpressure, were proposed for the Louisiana fields in the United States [1]-[3]. Other authors such as Bowers [4] studied new possible causes for overpressure such as, for example, expansion of fluids. However, these new methodologies demand data from pressure tests that are not available for shale rocks because of their low permeability.

Therefore, the development of numerical models to determine pore pressure (which would make it possible to analyze, estimate and quantify the impact of different variables) became a necessary tool. Terzaghi's effective stress theory [5] was used to develop 1D and 3D overpressure models. The variables considered were estimated using petrophysical and geochemical correlations updated at each depth. Other terms can be added depending on the source of the overpressure, since the differential equation that represents the model is linear.

In this research, the analysis of overpressure causes such as thermal stresses, fluid expansion and hydrocarbon generation are included [6]. The aquathermal effect is represented by the term proposed by [7]. It was necessary to implement the maturation model proposed by [8],[9] in order to estimate the contribution of hydrocarbon generation. This geochemical model estimates the kerogen fraction that is converted to oil during the first stage of maturation and subsequently, the fraction of the gas is calculated. With these fractions and the terms proposed by [10], the impact of the generation of hydrocarbons is calculated considering the cracking of kerogen-oil and oil-gas at pore pressure.

\section{THEORICAL FRAMEWORK}

\section{CAUSES OF OVERPRESSURE}

During drilling several events might occur, such as influxes, blowouts, losses of mud properties, increases in the \% of BGG $(\%$ Background Gas) and connection gas, landslides in the formation, and increases in the rate of cavings (splinter), among others. These events occur when the formation pressure exceeds the pressure of the mud. The causes of high formation pressures have been studied and classified by authors such as Osborne and Swarbrick, [11], who claimed that high pressures are a consequence of: 1) an increase in the compressive stress (reduction of pore volume) caused by an imbalance between compaction and tectonic compression, 2) growth in the volume of the pore fluid, which may be caused by the aquathermal effect, generation of hydrocarbons and clay diagenesis. 3) Movements of fluids and processes related to a difference in density between fluids and gases caused by hydraulic head, osmosis and buoyancy.

Similarly, Grauls [6] proposed that overpressures can be caused by mechanical stresses (sub-compaction being the most significant), thermal stresses (aquathermal expansion, cracking of kerogen to oil and cracking of oil to gas) or chemical stresses (among which the diagenesis of clay and fluid rock interaction are highlighted) (Figure 1). [6] also mentioned dynamic transfer through faults or lateral flow; osmosis, the artesian effect and buoyancy.

\section{MECHANICAL STRESS}

In sedimentary basins, dominated in particular by sands and shales, the weight of overload or vertical stress is the main contributor to the generation of overpressures [6]. However, changes in stress states can also contribute through compression stresses (horizontal and vertical) owing to tectonic forces. In relation to this latter aspect, the overpressure caused by these changes can be dissipated through fault planes [11].

Under normal compaction conditions, there is a balance between the overload generated by the weight of the strata and the reduction of the pore fluids. When this equilibrium is altered, undercompaction occurs. This means that the deposition rate of the sediments is higher than the rate of fluid ejection. In formations with high permeability, overpressure could be dissipated provided that their permeabilities are connected. However, in shales, undercompaction is encouraged by the reduction of permeability.

To determine overpressures, a normal compaction tendency can be established through sonic logs. When an unusual compaction tendency is exhibited, this indicates an excess of pressure. On the other hand, in a graph of effective stress versus sonic, if there is a normal compaction tendency, this reflects normal pressure. However, sometimes these estimations are not accurate; therefore, pressure profiles can be determined by using mathematical models such as Terzaghi's effective porosity-stress ratio and the law of continuity.

\section{THERMAL STRESS}

According to Grauls' classification [6], thermal stresses correspond to aquathermal expansion and the maturation of organic matter that is converted to oil and subsequently, to gas if the cracking continues. These causes may lead to an increase in the volume of pore fluid according to the classification proposed by [11].

Aquathermal effect. Aquathermal expansion consists of an increase in the volume of fluids in the pore as a result of temperature [12]. Certain conditions must be in place for this to arise, such as low permeabilities and a lower expansion of the pore volume 


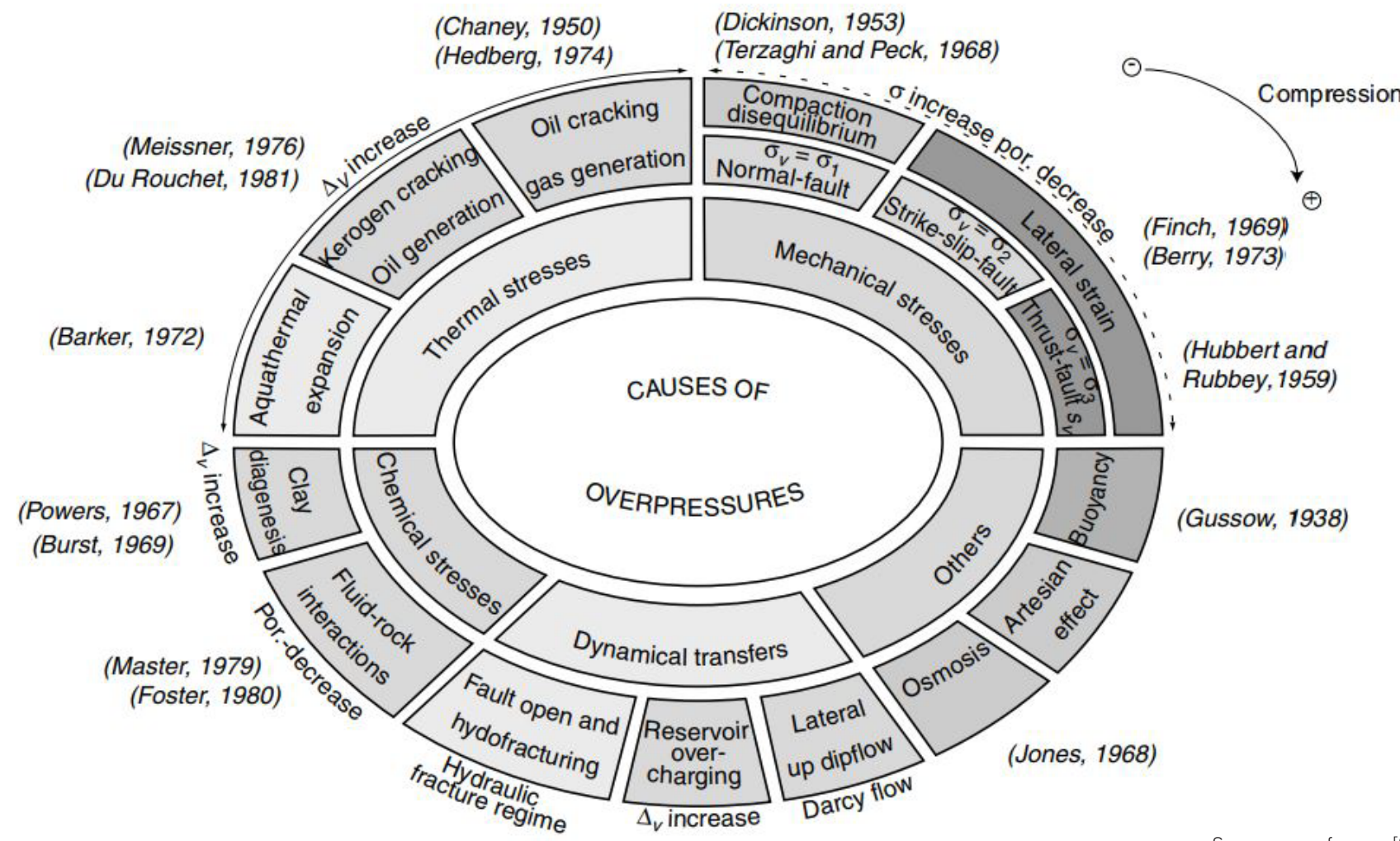

Source: see reference [6]

Figure 1 . Classification of causes of high pressures

compared to the thermal expansion of the water at a constant pressure. The literature presents diverse points of view in relation to aquathermal contribution. For example, Barker [12] through a pressure-temperature diagram and straight lines of equal density, affirmed that the aquathermal effect is significant. However, [7] used a mathematical model to show that its contribution is insubstantial, even under favorable geological conditions. This is due to the increase in pressure generated by the aquathermal effect being compensated by the decrease of fluid viscosity, caused by the increase in temperature, facilitating the flow of fluids and dissipating the pressure.

Hydrocarbon Generation. During sedimentation, part of the sediment may be organic matter. Organic matter is divided in 3 types of kerogen depending on its origin and they are classified using the Van Krevelen diagram according to the hydrogen index $(\mathrm{HI})$. This kerogen may undergo biogenic or thermogenic processes in terms of its burial conditions. According to Hedberg [13], biogenic processes, in which mainly methane is obtained, may occur at shallow depths, but as the burial continues, thermogenic processes begin.

Oil Generation. Once thermogenic processes begin, a series of conditions must be fulfilled so that the generation window can appear. The temperature must be higher than $200{ }^{\circ} \mathrm{F}\left(93^{\circ} \mathrm{C}\right)$ and the reflectance of vitrinite (Ro) greater than $0.7 \%$ [14]. The amount of oil generated will depend on the type of kerogen and its content of organic matter (TOC).

Meissner [15] reported that the kerogen-oil change is followed by an increase in fluid volume of $25 \%$. For this mechanism to be significant, the TOC content must be higher than 2\%) [16] and the reservoirs should have low permeabilities.

Generation of gas. There are two processes by which gas is generated: biogenic and thermogenic. At low temperatures (68-176 ${ }^{\circ} \mathrm{F}, 20-80{ }^{\circ} \mathrm{C}$ ), gas is generated by the decomposition of bacteria (biogenic gas). Then, organic matter is converted to oil (the burial process has continued) and finally to gas if the conditions of temperature and degree of maturity are favorable. The conditions for gas generation are a Ro greater than $2 \%$ and temperatures higher than $340{ }^{\circ} \mathrm{F}\left(175^{\circ} \mathrm{C}\right)$.

To determine the maturity index and predict in which section of the generation window the organic matter is found, a maturation model was generated. This model depends on the deposition history [17]. On the other hand, [18] A mathematical model was developed to estimate the effect of hydrocarbon generation, which is represented by a decrease in effective permeabilities and the increase in gas saturation. The contribution of oil to overpressure is marginal in rocks with organic matter content less than $2.5 \%$. For this effect to be significant, the TOC must be between $5-10 \%$. However, those values are only found in very rich rocks [18].

[10] proposed an additional term based on variations in densities as phase changes occur. This is in order to represent the effect of the generation of hydrocarbons, which is added to what was proposed for compaction by Terzaghi [5] and the term used in thermal effects [7]. 


\section{STATE OF THE TECHNIQUE}

Pore pressure is the pressure exerted by the fluids that are contained in the pores of the rock. This pressure increases due to overburden during sediment deposition and it is controlled by fluid flow and compaction [10]. If the precipitation rate allows for the expulsion of fluids, it will have hydrostatic pressure; but if the sediment precipitation rate is very high there will be abnormal pressure. The difference between the hydrostatic pressure and the current pore pressure is known as overpressure. Usually, pore pressure varies between hydrostatic pressure and lithostatic pressure. The pore pressure may have lower values than hydrostatic pressure during high erosion and uplifts, or when sand strata at a certain depth are connected to the surface through permeable facies. In other cases, the pore pressure may exceed the lithostatic pressure due to the generation of gas or the existence of permeable facies that are connected to deeper layers [10].

Correlations are usually used to calculate pore pressure, and the purpose of this research is to implement a numerical model that quantifies different causes of overpressure mentioned in the theoretical framework (chapter 2). The base model in this paper is proposed by Terzaghi [5] and other terms are added to quantify the other causes as thermal stresses. The assumptions of the initial model are shown below, and in Chapter 4 the model is explained along with all its terms.

\section{TERZAGHI'S MODEL 1923}

In Terzaghi's model, overpressure is related to incomplete mechanical compaction. This model establishes a relationship between the reduction in porosity and the compaction of sediments.

This model is widely used in $1 \mathrm{D}$ basin modeling, considering the following assumptions:

- The lithostatic pressure considers only the vertical component of the stress tensor as the maximum principal stress and is equal to the weight of overburden. The horizontal stresses are assumed to be proportional to the lithostatic pressure. Additionally, tectonic stresses are not present.

- Formation of pore pressure is caused by rapidly increasing overburden stress and the flow of fluids. Compaction determines how pressure is generated and distributed within the basin.

- It is assumed that the rock is saturated by a single fluid and that the flow of this fluid is controlled by permeabilities with pressure communication.

- The mechanical compaction of the pores takes into account the reassembly of grains and reduction in porosity caused by the leak of fluid from the pore. This reduction is controlled by Terzaghi's effective stress.

- Water is considered an incompressible fluid.

\section{EXPERIMENTAL DEVELOPMENT}

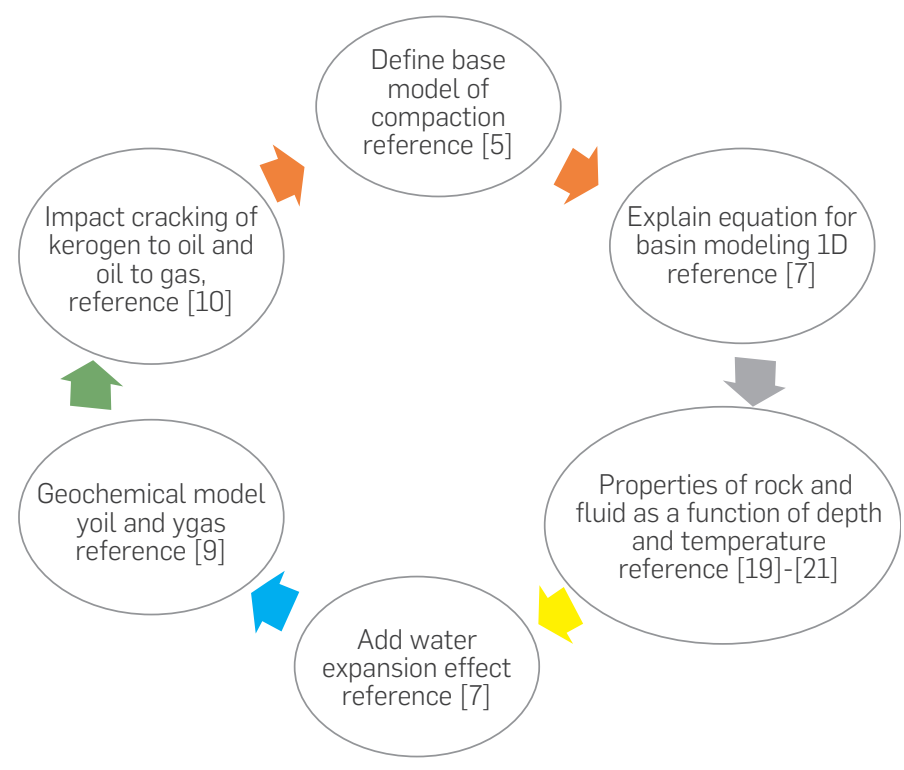

Figure 2. Workflow to demonstrate mathematical model

The procedure for obtaining a numerical model that calculates the pore pressure, including causes other than undercompaction, is explained below. The pressure equation is based on pore water balance. The force that drives the pore water is the overpressure gradient. Equation 1 shows Darcy's law in which a linear relation is established between the rate of discharge of the pore fluid, $V$, and the overpressure gradient, $\nabla P$. The proportionality factor is mobility and its value depends on the permeability of the rock, $k$, and the viscosity of the fluid, $\mu$.

$V=\frac{k}{\mu} \nabla P$

Luo and Vasseur [7] contributed, deriving the pore pressure equation by stating that the conservation of the rock material can be described using the continuity equation. With this analysis we come to Equation 2 where $V s$ is the speed of the rock material:

$\nabla V_{s}=\frac{1}{1-\emptyset} \frac{d \emptyset}{d t}$

The reduction of porosity $(\varnothing)$ by compaction is formulated by Terzaghi's law.

$\frac{d \emptyset}{d t}=-C \frac{d \sigma}{d t}$

Integrating Equations 1 to 3 and the assumptions from Terzaghi [5], the first model for the estimation of pore pressure considering the compaction variable was developed (see Equations 4 and 5). These equations indicate that overburden generates an increase in pressure and compaction. Both lithological parameters of permeability and compressibility control the flow of fluids and overpressure generation. Compressibility describes the ability of 
the rock to be compacted and control the influence of overburden in pore pressure. Permeability controls flow rates, circulation paths and pore pressure fields [10].

$-\nabla \frac{k}{\mu} \nabla P=-\frac{1}{1-\varnothing} \frac{d \emptyset}{d t}=\frac{C}{1-\emptyset} \frac{d \sigma}{d t}$

$\frac{C}{1-\varnothing} \frac{d P}{d t}-\nabla \frac{k}{\mu} \nabla P=\frac{C}{1-\varnothing} \frac{d P l}{d t}$

The terms are explained in the nomenclature except for the terms: porosity, compressibility, [19]-[21], as is described below.

Porosity and compressibility. The porosity was determined through the use of well logs. However, the compaction parameter $\alpha$ was estimated from the porosity model presented by [21]. This parameter establishes the variation of porosity as a function of depth (Equation 6). Subsequently, the compressibility of the rock was calculated by means of Equation 7 where $\alpha$ is the compaction coefficient, $\rho$ the density and $\varnothing$ the porosity calculated in the Equation 6.

$$
\begin{aligned}
\emptyset & =\emptyset_{o} e^{-\alpha H} \\
c r & =\frac{\alpha \emptyset}{\Delta \rho g(1-\emptyset)}\left(p s i^{-1}\right)
\end{aligned}
$$

Equation 6 can only be used for areas of normal compaction where the pressure is hydrostatic; thus, Equation 8 shows a expression where the porosity is related to the effective stress [22].

$\emptyset=\emptyset_{o} e^{-b \sigma}$

Where the parameter $b$, is defined by the Equation 9

$b=\frac{\alpha}{\Delta \rho g}\left(p s i^{-1}\right)$

Permeability: Equation 10 shows permeability as a function of porosity. It was proposed by [5] for fine-grained rocks. This model was used for the evaluation of the case study.

$$
k=\lambda \emptyset^{5}
$$

Where the dimensionless parameter $\lambda$ varies between $10^{-3}-10^{-7}$.

The value of $\lambda$ depends on the content of clay, being $10^{-3}$ for clean sands and $10^{-7}$ for shale, as the volume of shale varies between 0 and $1, \lambda$ is between those two ranges $\left(10^{-3}-10^{-7}\right)$.

Viscosity. Equations 11 and 12 relate changes in water viscosity to variations in temperature. [20] presented this correlation for temperature ranges between $0-300^{\circ} \mathrm{C}$.

$$
\frac{1}{\mu}=\left(5.38+3.8 A-0.26 A^{3}\right) 10^{3}
$$

Where:

$$
A=(T-150) / 100
$$

The second model, proposed in this paper, also considers thermal stresses according to Grauls' classification [6] to the mechanical stress of compaction (Equation 5), generating a change in the volume of the pore fluids [11]
Equation 13 shows the second developed model, which includes water expansion, where $\beta \mathrm{dT} / \mathrm{dt}$ represents the aquathermal term [7].

$\frac{C}{1-\emptyset} \frac{\partial P}{\partial t}-\nabla \cdot \frac{K}{\mu} \frac{\partial P}{\partial z}=\frac{C}{1-\varnothing} \frac{\partial P L}{\partial t}+\beta \frac{d T}{d t}$

The terms of Equation 13 are the same as in Equation 5, but additionally there is the isobaric thermal expansion coefficient $\beta$.

An additional new mechanism, oil generation, was included in the model developed. This mechanism was studied [18] who proposed a two-phase model. [18] stated that the generation of oil is represented by the decrease in relative permeabilities and the change in saturation. In addition, they concluded that the oil effect is only important if there is high total organic content (TOC). [10], proposed the term $(1 / \rho l-1 / \rho k) d u l / d t$ to quantify this effect.

For purposes of implementation of this new mechanism, the contribution of this work was aimed at developing a maturation model that applies Equation 14 in order to understand the generation of oil at each depth and not as a total contribution.

$\frac{\partial \mathrm{x}}{\partial \mathrm{t}}=-k x$

Equation 14 is for a simple reaction type, used for most sequential and parallel reaction schemes, and is the unimolecular forward reaction from an initial reactant $X$ of mass $x$ to the product $Y$ of mass $y$. The temperature dependency of the reaction rate $k$ is usually described by the Arrhenius law with two parameters; the frequency factor $\mathrm{A}$ and the activation energy $\left(E_{a}\right): \mathrm{k}=\mathrm{A} \cdot \mathrm{e}-E_{a} / \mathrm{RT}$. The parameters for the geochemical model are shown in Table 1.

The third model for the evaluation of pore pressure, which includes compaction, the aqua-thermal stresses and the generation of oil, is given in Equation 15.

$$
\begin{aligned}
& \frac{C}{1-\varnothing} \frac{d P}{d t}-\nabla \frac{k}{\mu} \frac{d P}{d Z}=\frac{C}{1-\varnothing} \frac{d P l}{d t}+\beta \frac{d T}{d t}+y o i l * \\
&\left(\frac{1}{\rho l}-\frac{1}{\rho k}\right) \frac{d u l}{d t}
\end{aligned}
$$

where the terms $\rho l=0.85 \mathrm{~g} / \mathrm{cm}^{3}$ and $\rho \mathrm{k}=0.95 \mathrm{~g} / \mathrm{cm}^{3}$ represent the density of the oil and of the kerogen respectively, and $u l$ indicates the variation of the density that can be expressed as a function of the variation of the pressure.

[18] studied the effect of gas on pore pressure, while [10] established a term to quantify the effect of gas generation. The results were similar.

The term that represented the effect of gas, $(1 / \rho v-1 / \rho k) d u v / d t$, was modified to analyze the impact of gas generation as a function of depth. This term, which is similar to the case of oil generation, was considered in Equation 15, to ultimately obtain a model for the evaluation of pore pressure that includes all the causes presented in this study (Equation 16).

$$
\begin{aligned}
& \frac{C}{1-\emptyset} \frac{d P}{d t}-\nabla \frac{k}{\mu} \frac{d P}{d Z}=\frac{C}{1-\emptyset} \frac{d P l}{d t}+\beta \frac{d T}{d t}+ \\
& \text { yoil }\left(\frac{1}{\rho l}-\frac{1}{\rho k}\right) \frac{d u l}{d t}+\operatorname{ygas}\left(\frac{1}{\rho v}-\frac{1}{\rho k}\right) \frac{\partial \mu v}{\partial t}
\end{aligned}
$$


Table 1. Parameters for the geochemical model

\begin{tabular}{|c|c|c|c|c|c|c|c|c|c|c|}
\hline & & \multicolumn{3}{|c|}{ KEROGEN I } & \multicolumn{3}{|c|}{ KEROGEN II } & \multicolumn{3}{|c|}{ KEROGEN III } \\
\hline \multicolumn{2}{|c|}{ Stage } & $\mathrm{Xi}$ & $\mathrm{Ei}$ & A & $\mathrm{Xi}$ & $\mathrm{Ei}$ & A & $\mathrm{Xi}$ & $\mathrm{Ei}$ & A \\
\hline \multirow{6}{*}{1} & 1.1 & 0.024 & 10 & 4.75E+04 & 0.022 & 10 & $1.27 \mathrm{E}+05$ & 0.023 & 10 & $5.20 \mathrm{E}+03$ \\
\hline & 1.2 & 0.064 & 30 & $3.04 E+16$ & 0.034 & 30 & $7.47 \mathrm{E}+16$ & 0.053 & 30 & $4.20 \mathrm{E}+16$ \\
\hline & 1.3 & 0.136 & 50 & $2.08 E+25$ & 0.251 & 50 & $1.48 \mathrm{E}+27$ & 0.072 & 50 & $4.33 E+25$ \\
\hline & 1.4 & 0.152 & 60 & $3.98 \mathrm{E}+30$ & 0.152 & 60 & $5.52 E+29$ & 0.091 & 60 & $1.97 \mathrm{E}+32$ \\
\hline & 1.5 & 0.347 & 70 & $4.47 E+31$ & 0.116 & 70 & $2.04 E+35$ & 0.049 & 70 & $1.20 E+33$ \\
\hline & 1.6 & 0.172 & 80 & $1.10 \mathrm{E}+34$ & 0.12 & 80 & $3.80 \mathrm{E}+35$ & 0.027 & 80 & $7.56 \mathrm{E}+31$ \\
\hline 2 & 2 & 1 & 54 & $3.20 E+25$ & 1 & 54 & $3.20 E+25$ & 1 & 54 & $3.20 E+25$ \\
\hline 3 & 3 & 1 & 57 & $3.16 \mathrm{E}+26$ & 1 & 59 & $3.16 E+26$ & 1 & 59 & $3.16 E+26$ \\
\hline
\end{tabular}

Source: Reference [18]

The density of the gas varies with the pressure at each depth, assuming constant molecular weight $19 \mathrm{~g} / \mathrm{mol}$. That of the liquid and kerogen are taken as constants and the fractions of the yoil and ygas are determined by Equation 14, indicating that hydrocarbon fraction has been generated at each depth as a function of pressure and temperature.

\section{RESULTS}

The model presented by Equation 5 was applied to a well in the Middle Magdalena Valley, which exhibited a high-pressure zone that could not be justified by sub-compaction. Figure 3 shows the pore pressure of the basin modeling. The chart was compared with correlations that only quantify the subcompaction effect. The terms of Equation 5 as a function of depth or temperature were calculated by means of Equations 6 to 12, and Pl that refers to the lithostatic pressure or vertical stress, is calculated by the density log.

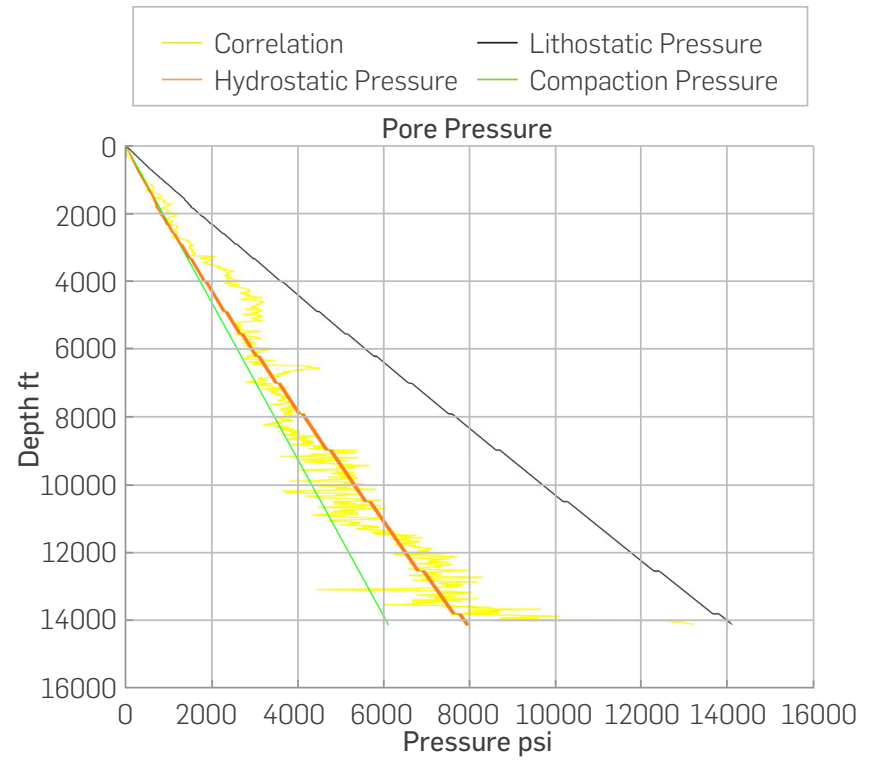

Figure 3 . Pore pressure through basin modeling and correlation (Compaction)

Figure 3 shows the pressure profile for the study well. Comparing the orange curve obtained by modeling the basin and the yellow one obtained by conventional correlations, it is observed that despite using two different methodologies, both curves quantify pore pressure and present similar trends. Also, both curves are within the range of normal pressure which is a value that's higher than the hydrostatic pressure (Green curve) and lower than the lithostatic pressure (Black curve).

On the other hand, the next cause of overpressure to be calculated is the effect of water expansion. This cause refers to the impact of temperature on the water of the pores and on pressure, and it can only be calculated using differential equations and not correlations. For that reason, it is necessary to add the respective aquathermal term to Equation 5 to obtain Equation 13. The profile obtained is presented in Figure 4.

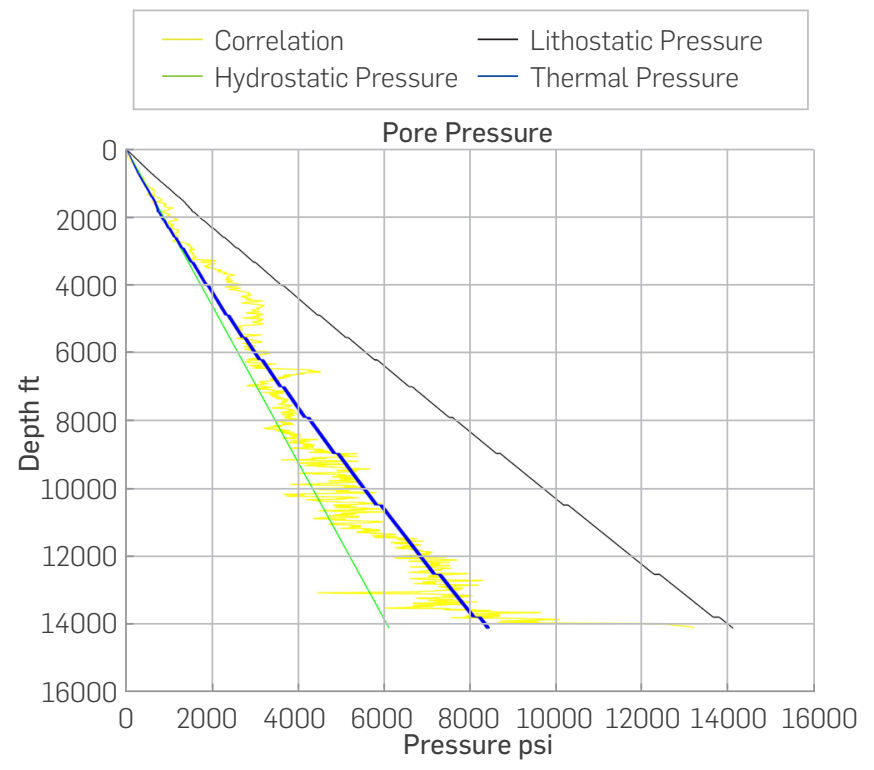

Figure 4 . Pore pressure through basin modeling and correlation (Compaction and thermal)

Figure 4 shows the pore pressure curve when calculating only the impact of the compaction (orange curve), and when the water expansion effect is included (blue curve) it shows consistency with what is found in the literature. The impact of water expansion on pore pressure is very small because an increase in temperature causes a decrease in viscosity which benefits the movement of fluids and maintenance of pressure [7]. This is demonstrated on Figure 3 where the pore pressure at $8000 \mathrm{ft}$ is 4094 psi for both 


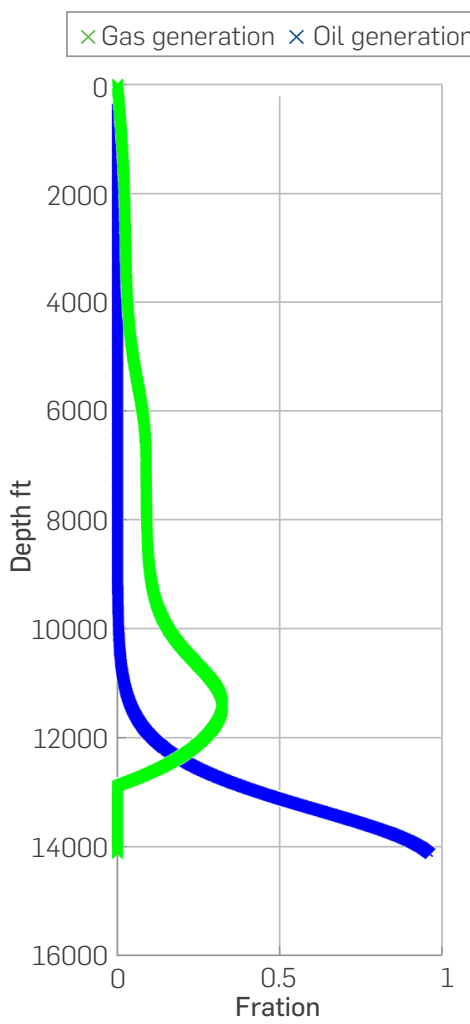

(a)

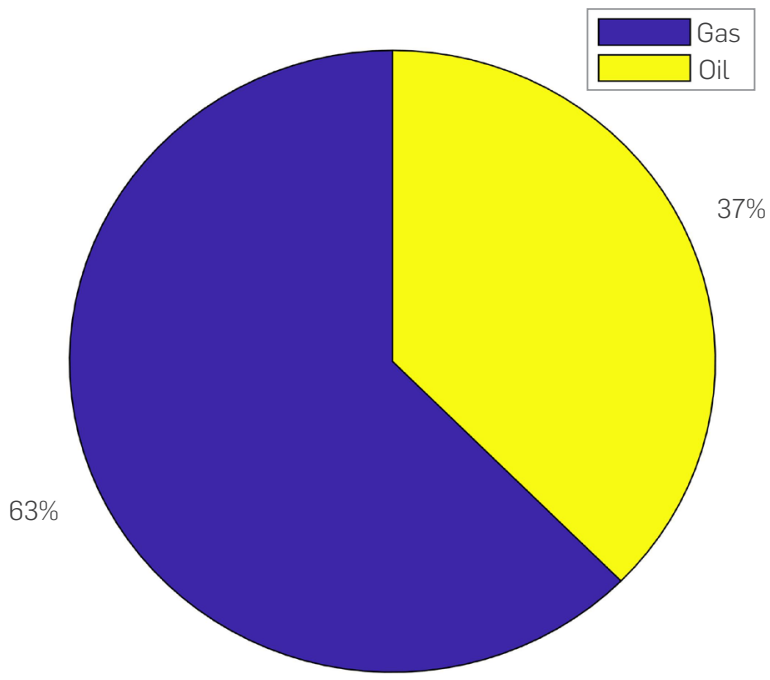

(b)

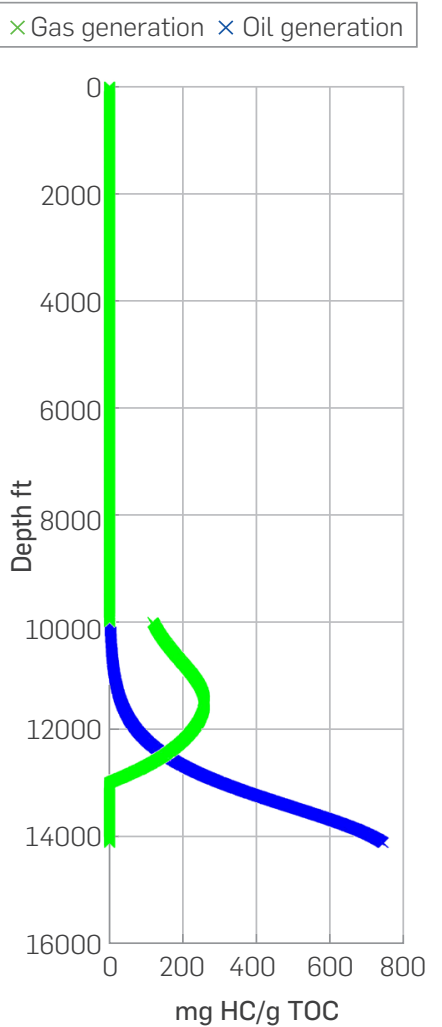

(c)

Figure 5 . a) Hydrocarbon generation window, b) example of fraction generated at a certain depth, c) amount of hydrocarbons, oil and gas generated as a function of TOC and the type of kerogen.
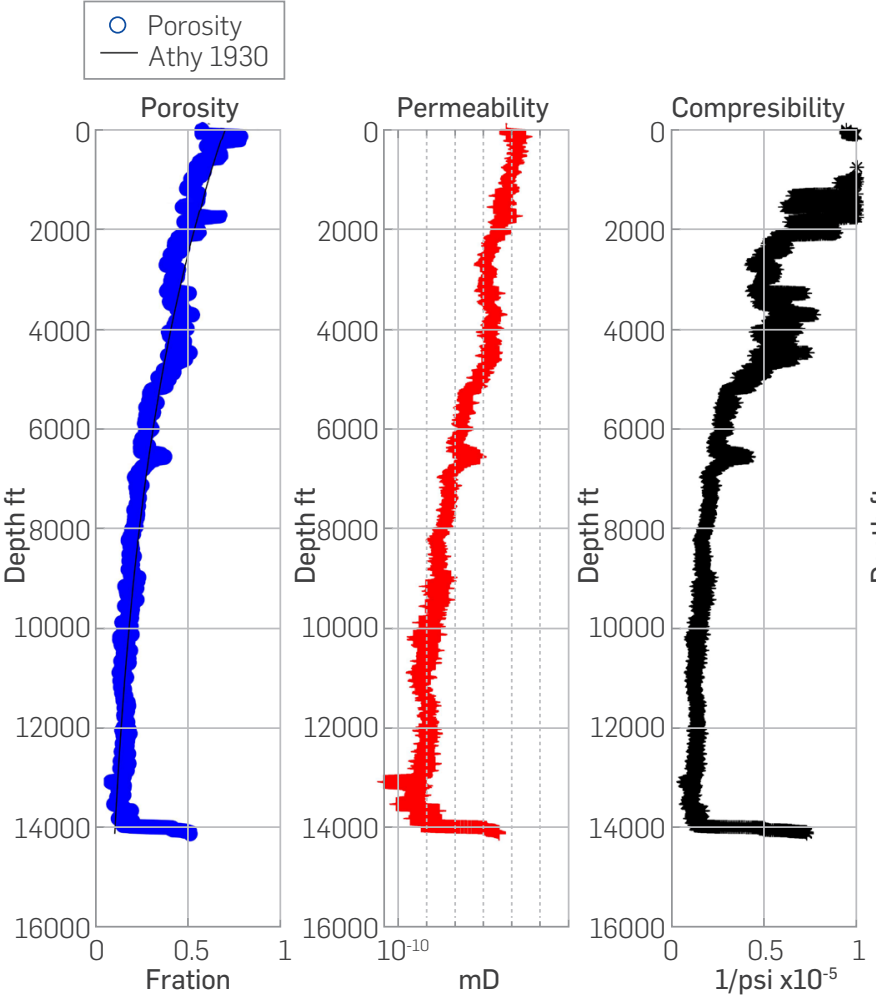

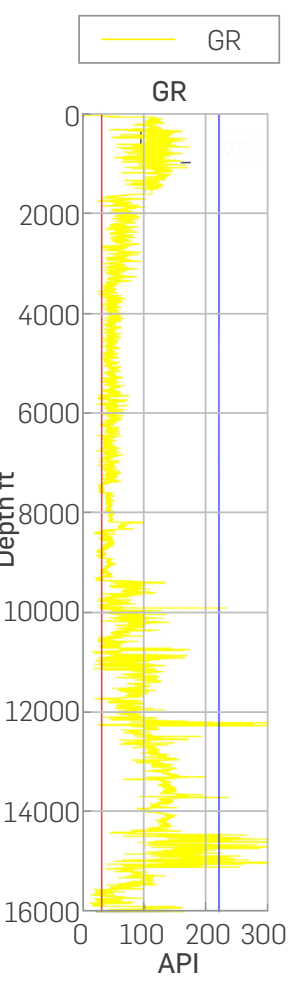

Figure 6 . Petrophysical model for the study well subcompaction (Figure 3) and thermal effect (Figure 4) curves. Then, the effect of oil generation was estimated using Equation 15. This equation needs to quantify the term yoil that depends on geochemical properties such as TOC and type of kerogen through Equation 14, generating a geochemical model as evidenced in Figure 5: a) the hydrocarbon generation window, b) the amount of oil that can be generated at a certain depth c) the amount of hydrocarbons generated according to the TOC, and the type of kerogen in the case study, while the term ygas is also calculated.

Once the geochemical model is completed (Figure 5), it is necessary to couple it with the petrophysical model (Figure 6) to quantify other causes of overpressure, such as thermal stresses.

The curves in Figure 6 were generated with Equations 6 through 12 . With this information, we proceed to quantify the effect of oil generation (Equation 15) and gas generation (Equation 16). The values of oil density, kerogen density and molecular weight of the generated gas are taken as constants according to the case study, and the density of the gas changes according to the pressure. 

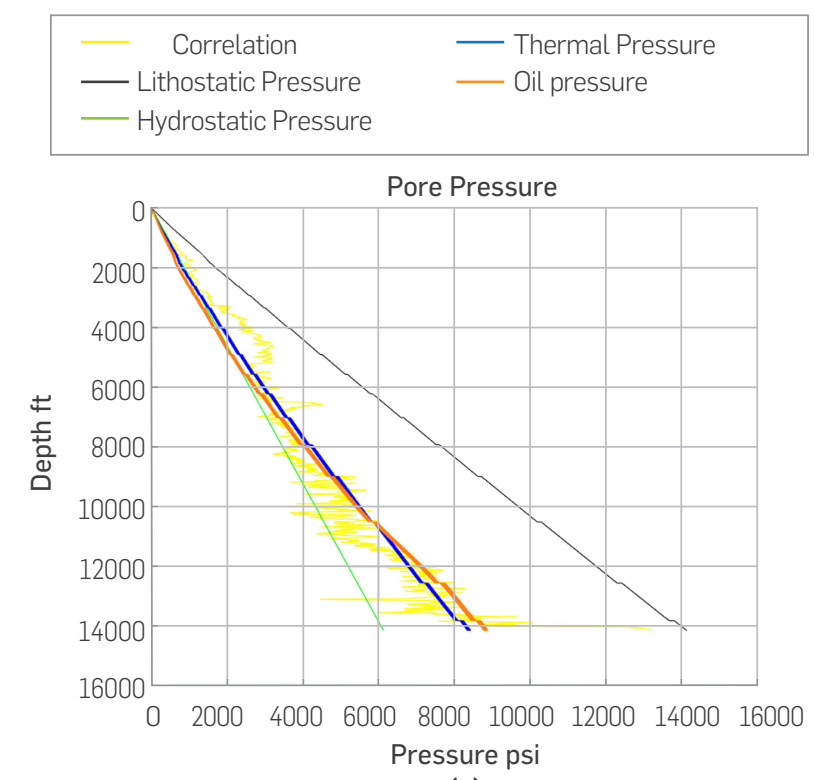

(a)
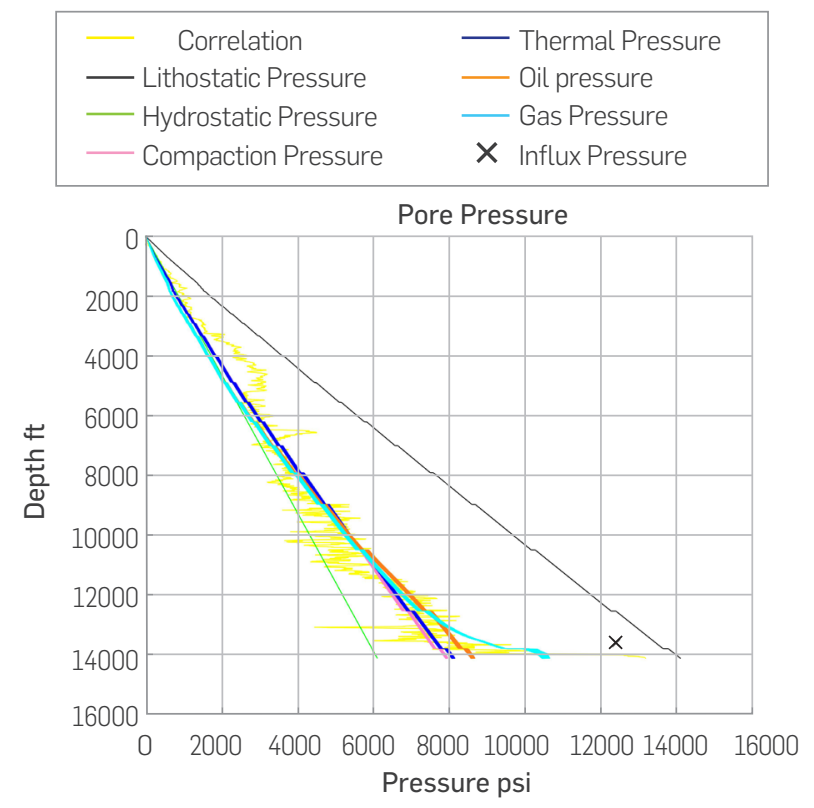

(b)

Figure 7 . Pore pressure through basin modeling and correlation. 6 (a) Effect oil, 6 (b) Effect gas

\section{RESULTS ANALYSIS}

The first result for pore pressure is recorded in Figure 3 and this results from applying Equation 5, which includes only undercompaction and when compared with pressure values calculated with correlations, the curves showed the same trend.

The effect of water expansion on overpressure was analyzed as shown in Figure 4, where it is noted that this phenomenon does not have much impact due to the decrease in viscosity with temperature. Then, to implement the effect of hydrocarbon generation, the geochemical model is constructed using the constants from Table 1, Equation 14 and that shown in Figure 5; subsequently, it is complemented with the petrophysical model in Figure 6 to finally obtain the pressure values considering the effect of compaction, water expansion and hydrocarbon generation shown in Figure 7.

The figure shows the impact induced by thermal stress in pore pressure. The effect of oil is set out in Figure 7a). However, it is noticeable that its contribution is lower than gas contribution, which is shown in Figure 7b). This is due to the fact that gas expansion is more substantial than oil expansion. Some authors state that a barrel of oil can be converted to $3,000 \mathrm{ft}^{3}$ of gas. By normalizing the overpressure, the impact of the other causes was assessed. Thermal stresses reach a contribution of $20 \%$ at a depth of $13,500 \mathrm{ft}$. At depths beyond $13,500 \mathrm{ft}$., the contribution of thermal stresses rises to more than $20 \%$ because all the oil can be converted to gas (Figure 8). The previous idea depends on the presence of a seal rock that prevents gas migration, maintaining pore pressure. The gas has lower viscosity than water even at high temperatures, but the impact of water expansion is not maintained, easing fluids flow during the deposition of sediments. The transformation of kerogen to oil and oil to gas occurs in low permeability rocks and this fluid remains in the rock, increasing pore pressure, unless it fractures and allows its migration.

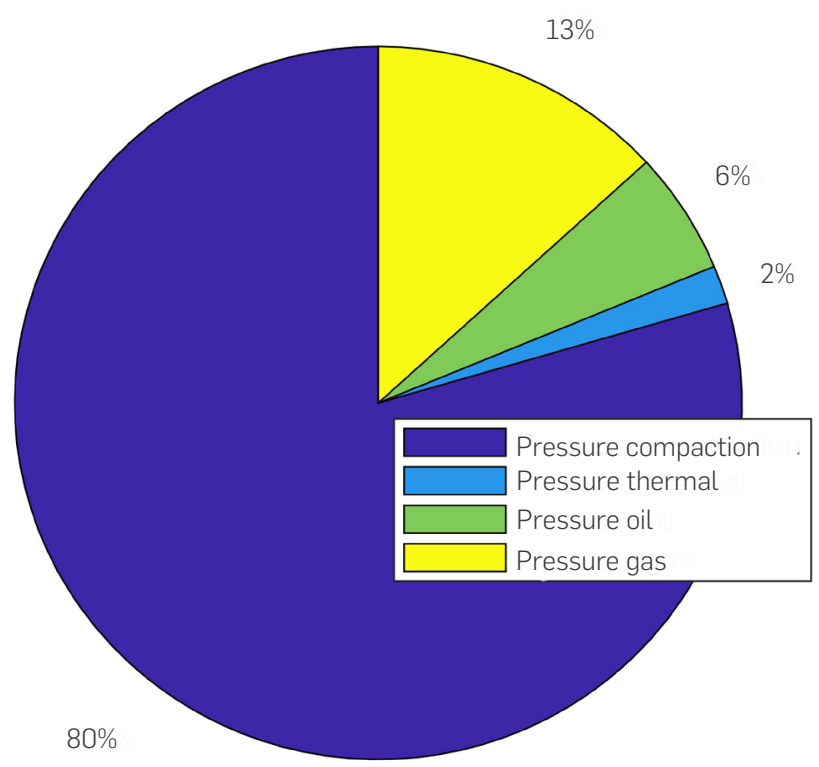

Figure 8 . Effect of each mechanism on the pore pressure

\section{FIELD DATA.}

Once the mechanisms that generate the overpressure (previously mentioned) were analyzed the results were studied and validated by comparing them with the field reports, showing an influx of gas in the well studied, with a high-pressure point represented by letter $x$ (Figure 9). This pressure was not predicted, and conventional methods are not able to model it. Through the model used in this research, a value very close to the pressure of the influx is obtained by quantifying the thermal stresses present in the formation with a type 2 kerogen, but it does not obtain the total value of the influence, which indicates that other causes of overpressure may exist. 


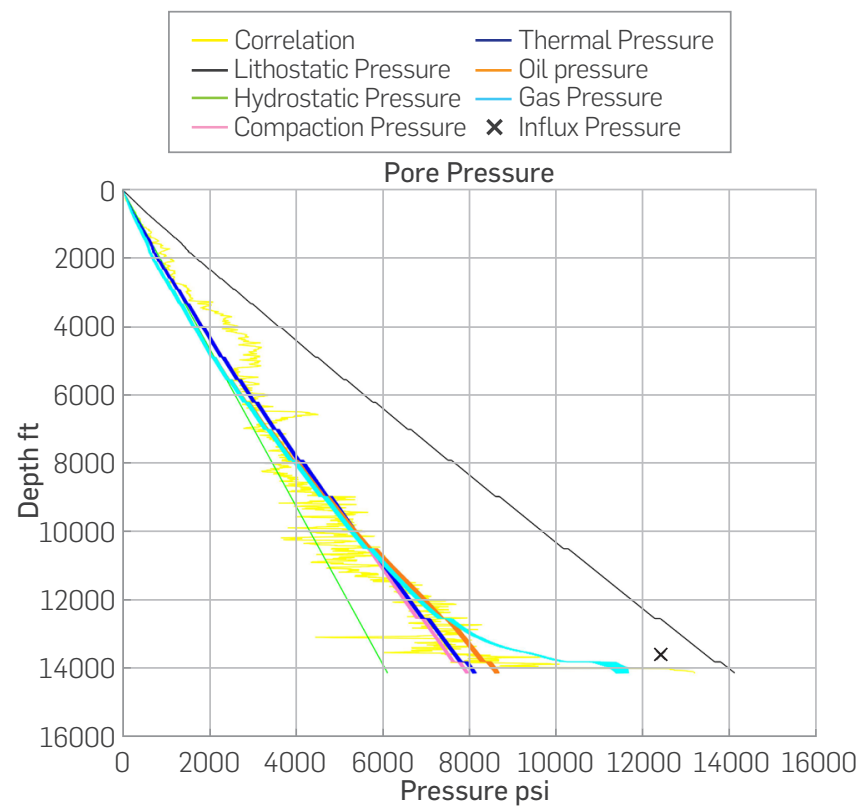

Figure 9 . Pore pressure through basin modeling greater geochemical potential

Due to the pressure curve obtained from the mechanisms studied in this work does not accurately represent the measured value (Figure 9), it can be said that there are other effects that can cause overpressure, such as dynamic transfer. It can be noticed on this work that, at greater depths, the possibility of hydrocarbon generation improves (Figure 5) increasing the value of yoil and ygas, encouraging overpressure if there is also proper geochemical potential (TOC exceeding 3\%). The impact of overpressure could exceed $20 \%$. It is worth noting that the contribution increases as the depth does. In Figure 10, an analysis regarding the contribution of the causes of overpressure studied in greater depth is made to

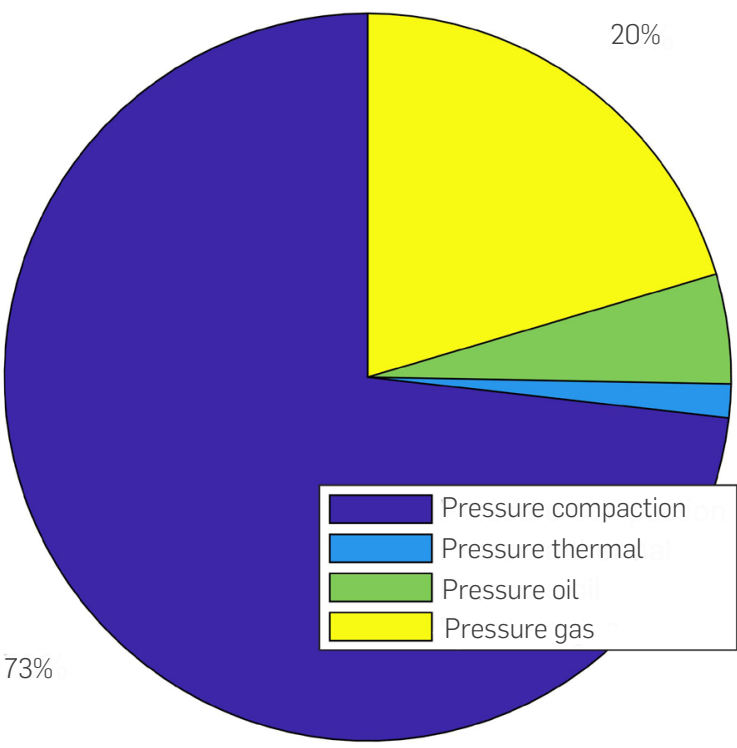

Figure $\mathbf{1 0}$. Effect of each mechanism on the pore pressure greater geochemical potential demonstrate that the excess of overpressure may be due to the impact of thermal stress at greater depths.

In the case of the specific field considered in this article as a reference, the formation that presented the influx of gas, exhibits high pressures that are not demonstrated with the thermal stresses at that depth as explained in the previous idea, but instead a greater depth. For example, there is a larger generation of hydrocarbons at 14100 feet, which is 500 feet deeper than the depth of influx; the contribution already reaches $27 \%$ as indicated in figure $10,7 \%$ higher than that seen at 13500 feet (Figure 8) justifying the overpressure registered at the depth of the influx. The results obtained using this methodology are similar to those presented in [22] where pore pressure was estimated by modeling basins using commercial software.

\section{CONCLUSIONS}

Compaction is the main cause of overpressure. If compaction is low, there will be a normal pressure. However, if the sedimentation rate is high, sub compaction will be generated, thus increasing the pore pressure. This pressure can be estimated by correlations in conventional reservoirs. Nevertheless, correlations are not as effective in some unconventional reservoirs that present fluid expansions because they provide lower pore pressure values.

The aquathermal effect is not significant in overpressure generation since it was found that the excess in pressure is compensated by the decrease in viscosity. This reduction in viscosity facilitates the dissipation of pressure.

Coupling both petrophysical and geochemical models makes it possible to estimate thermal stresses and add them to the compaction effect. It was observed that the impact of oil generation is close to $3 \%$ and the effect of gas generation is greater than $17 \%$. This expansion of fluids takes place when kerogen is converted to oil and later to gas, which generates a significant change in the volume of the fluid.

The hydrocarbon fraction generated increases as the depth increases; therefore, the potential of pressure increases, and its contribution may exceed $20 \%$. If geological formations are connected to shallow formations, dynamic transfer may occur. This would justify high pressures that cannot be accounted for by thermal stress.

\section{ACKNOWLFDGEMIENIS}

The authors thank GOD for everything, as well as the Well Stability Research Group, the Industrial University of Santander, Colombian Petroleum Institute for the advice provided and Darwin Mateus Tarazona, thanks for your help. 


\section{REFERENCES}

[1] Hottmann C. y Johnson, R. Estimation of Formation Pressures from Log-Derived Shale Properties, Journal of Petroleum Technology. 1965

[2] Eaton B.,1975, The Equation for Geopressure Prediction from Well Logs, AIM

[3] Zhang, J. Pore pressureprediction from well logs: Methods, modifications, and new approaches. Earthscience Reviews, 108(1-2), 50 - 63 (2011)

[4] Bowers G.L. Pore Pressure Estimation From Velocity Data: Accounting for Overpressure Mechanisms Besides Undercompaction, SPE Drilling \& Completion. 1995

5] K. Terzaghi. Die Berechnung der Duerchl"assigkeitsziffer des Tones im Verlauf der hydrodynamischen Spannungserscheinungen. Szber Akademie Wissenschaft Vienna, Math-naturwissenschaft Klasse Ila, (132):125-138, 1923.

[6] D. Grauls Overpressures: Causal Mechanisms, Conventional y Hydromechanical Approaches Oil \& Gas Science y Technology - Rev. IFP, Vol. 54 (1999), No. 6, pp. 667-678

[7] X. Luo y G. Vasseur. Contributions of compaction y aquathermal pressuring to geopressure y the influence of environmental conditions. AAPG Bulletin, 76(10):15501559, 1992

[8] Tissot,B ., Espitalie, .: L'evolution thermique de la matiere organique des sediments: application d'une simulation mathematique Rev. Inst Fr. Petr.30, 743 777( 1975)
[9] Tissot, B., y D. H. Welte, 1984, Petroleum formation y occurrence (2d ed.): Berlin, Springer-Verlag, $699 p$

[10] T. Hantschel, A.I. Kauerauf, Fundamentals of Basin y Petroleum 31 Systems Modeling, DOI 10.1007/9783-540-72318-9 2, C Springer-Verlag Berlin Heidelberg 2009

[11] M. J. Osborne y R. E. Swarbrick. Mechanisms for generating overpressure in sedimentary basins: A reevaluation. AAPG Bulletin, 81:1023-1041, 1997.

[12] Barker C 1972 Aquatermal pressuring: role of temperature in development of abnormal pressure zone. AAPG Bulletin v. 56 p. 2068-2071

[13] Hedberg, H.D. (1974) Relation of Methane Generation to Undercompacted Shales, Shale Diapirs, y Mud Volcanoes. Am. Assoc. Pet. Geol. Bull., 58, 668-673.

[14] Spencer, C. W., 1987, Hydrocarbon generation as a mechanism for overpressuring in Rocky Mountain region: AAPG Bulletin.v. 71 , p. 368-388.

[15] Meissner, F. F. Petroleum geology of the Bakken Formation, Williston Basin, North Dakota y Montana. Montana Geological Society, Billings, p. 207 - 227 1978. Proceedings of 1978 Williston Basin Symposium, September 24-27

[16] Spencer, C.W. y Law, B.E., 1981. Overpressured, Lowpermeability gas reservoirs in Green River. Washakie, y Great Divide Basins, southwestern Wyoming. Bull., Am. Assoc. Pet. Geol., 65: 569.
[17] Waples, D.W., 1980. Time y temperature in petroleum formation - application of Lopatin's method to petroleum exploration. BulL, Am. Assoc. Pet. GeoL, 64: 916-926.

[18] X. Luo y G. Vasseur. Geopressuring mechanism of organic matter cracking: Numerical modeling. AAPG Bulletin, 80(6):856-874, 1996

[19] Terzaghi, K., 1925, Principles in soil mechanics, III. Determination of the permeability of clay: Engineering News Record, v. 95, p. 832-836.

[20] Mercer, J. W., G. F. Pinder, y I. G. Donalson, 1975 A Galerkinfinite element analysis of the hydrothermal system at Wairakei, New Zealy: Journal of Geophysical Research, v. 80, p. 2608-2621.

[21] L. F. Athy. Density, porosity y compaction of sedimentary rocks. American Association of Petroleum Geophysicists Bulletin, (14):1-24, 1930.

[22] Hubbert M. K., and Rubey W.W. 1959 Mechanics of fluid filled porous solids and its application to averthrust faulting 1 , role of fluid pressure in mechanics of overthrust: Geological society of American Bulletin v. 70 pl15 - 166

[23] Vargas, D. A., Calderón, Z. H., Mateus, D. C., Corzo R., \& Acevedo, O. J. (2014, November 24). Mathematical Model to Quantify the Contribution of Thermal Stresses in Pore Pressure, Additional to the Compaction Effect. International Society for Rock Mechanics.

\section{NOMENCLATURE}

$\nabla \mathrm{V}_{\mathrm{s}} \quad$ Velocity of de moving rock

b Coefficient of compaction overpressure zones 1/psi

$\nabla P \quad$ Pressure variation

$\alpha \quad$ Coefficient of compaction

Pwf Bottomhole pressure welbore

Pi Pore pressure

k Permeability

h Thickness

Фо Porosity

gra $\mathrm{T}$ Temperature

Swr Saturation

S Skin

rw rwellbore

Bo Volumetric Factor

Ho Viscocity

t Time

Q Flow

Cf Compressibility

$\Delta t_{\text {log }} \quad$ Time measure of log

$\Delta t_{f l} \quad$ Time measure of fluid

$\Delta t_{m a} \quad$ Time measure of matrix

$\mathrm{psi} / \mathrm{ft}$

$1 / \mathrm{ft}$

$M p$

$M p$

md

$\mathrm{m}$

${ }^{\circ} \mathrm{C} / \mathrm{km}$

$\mathrm{m}$

$\mathrm{bb} / \mathrm{STB}$

$\mathrm{cp}$

$\mathrm{hr}$

$\mathrm{Bb} / \mathrm{D}$

$1 / \mathrm{Mp}$

$\mathrm{us} / \mathrm{ft}$

$\mathrm{us} / \mathrm{ft}$

us/ft

$1 \mathrm{~m}=\quad 3.28 \mathrm{ft}$

$1 \mathrm{MP}=145 \mathrm{psi}$

$\mathrm{H}=\quad$ Depth

$\mathrm{T}=\quad$ Temperature

${ }^{\circ} \mathrm{C}$ 